\title{
Factors associated with high antimicrobial use in young calves on Dutch dairy farms: A case-control study
}

\author{
M. M. C. Holstege, ${ }^{* 1}$ A. J. G. de Bont-Smolenaars, ${ }^{*}$ I. M. G. A. Santman-Berends, ${ }^{* 1}$ \\ G. M. van der Linde-Witteveen, ${ }^{*}$ G. van Schaik, ${ }^{*}{ }^{1}$ A. G. J. Velthuis, ${ }^{*}$ and T. J. G. M. Lam ${ }^{*} \dagger$ \\ ${ }^{*}$ GD Animal Health, PO Box 9, 7400 AA Deventer, the Netherlands \\ †Faculty of Veterinary Medicine, Department of Farm Animal Health, Utrecht University, PO Box 80151, 3508 TD Utrecht, the Netherlands
}

\section{ABSTRACT}

Since 2012, the Dutch Veterinary Medicine Authority reports antimicrobial usage (AMU) in young calves $(<56 \mathrm{~d})$ on dairy farms on an annual basis. The AMU distribution in this age group is skewed, with a low AMU in young calves on the majority of dairy farms and a high AMU in a relatively small number of farms. This results in a notable difference between the mean and median AMU. To further reduce the mean AMU, the AMU on the high-AMU farms must be decreased. The objective of this study was to evaluate the association between both young stock management and an indication of the farmers' mindset and AMU in young calves on Dutch dairy farms with a high and low AMU in young calves. This knowledge may be helpful in decreasing AMU in young calves on high-AMU farms. We performed a case-control study in which 200 dairy farms (100 with high AMU and 100 with low AMU in young calves) participated. Case farms were defined as farms with an animal daily-defined dose at the farm level in young calves $>28$ in 2012 and 2013, based on the 90th percentile of the use of antimicrobials in young calves in 2012. Control farms had an animal daily-defined dose at the farm level in young calves of $<0.5$ in 2012 and 2013, which was determined to be low use. A questionnaire was conducted about general farm and young stock management, hygiene, housing, vaccination, and calf health. An indication of the farmers' mindset with regard to AMU and treatment of sick calves was determined by including statements (agree/ disagree) in the questionnaire. In addition, routinely collected data on herd size, growth in herd size, replacement, and calf mortality were available for analysis. Dairy farmers that immediately started antimicrobial treatment in sick calves had higher odds of being in

Received December 6, 2017.

Accepted June 14, 2018.

${ }^{1}$ Corresponding authors: g.v.schaik@gdanimalhealth.com, and I.santman@gddiergezondheid.nl the high-AMU group than farmers who started treatment of sick calves with supportive nonantimicrobial therapy. Other variables associated with a high AMU in young calves included housing calves on partially slatted floors, a high prevalence of respiratory disease, an unfavorable Salmonella status, and not agreeing with the statement "Young stock need specific management." Both dairy farm management and opinions of dairy producers regarding AMU, indicative of mindset, are important when distinguishing farms with high and low AMU in young calves. Although the rationale behind mindset warrants more research, likely a change in both aspects seems to be required to reduce the AMU in young calves on dairy farms.

Key words: management, mindset, antimicrobial usage, young calves

\section{INTRODUCTION}

In 2008, the Dutch government requested the livestock industry reduce antimicrobial usage (AMU) by $70 \%$ in 2015, using 2009 as the reference year. The Dutch Veterinary Medicine Authority (SDa) monitors AMU in the Netherlands and reports annually on the national trends in AMU, which is presented as the animal dailydefined dose at the farm level $\left(\mathbf{D D D A}_{\mathbf{F}}\right)$. The DDDA is calculated by dividing the amount of total treated weight by the total weight of cattle present per farm annually (SDa, 2013b). Between 2009 and 2014, the overall veterinary AMU for the different sectors in the animal industry decreased substantially (SDa, 2015).

The AMU of cattle in the Netherlands is evaluated for 4 different farm types: suckler cows, dairy, young stock rearing, and beef farms (veal is reported separately from cattle). For dairy farms, the mean DDDAF was 2.9, 2.8, and 2.3 in 2012, 2013, and 2014 respectively (SDa, 2013a, 2014, 2015). Data on AMU on dairy farms is provided in total and stratified into dry cow therapy, intramammary treatments in cows $>2$ yr old and the treatment of young calves $(0-56 \mathrm{~d}$ old $)$. The main indications for AMU in calves are respiratory and digestive 
disorders or diarrhea, both in the dairy and veal sector (González et al., 2010; Pardon et al., 2012). The AMU distribution in young dairy calves is skewed. Many dairy farms have a low AMU in young calves, whereas a relatively small number of farms have a high AMU. This results in a notable difference between the mean and median AMU in young calves (SDa, 2013a, 2014, 2015). Although AMU in young calves has decreased considerably over the years in our country (SDa, 2013a, 2014, 2015), it remains an important issue given the unequal distribution of the prevalence of antimicrobial resistance across age groups, with higher levels in younger animals (Hinton et al., 1984, 1985; Zhang et al., 1998). Furthermore, the antimicrobial resistance in young animals has been reported to increase over time, for example with regard to Escherichia coli (Chirila et al., 2017).

On dairy farms with a high $\mathrm{DDDA}_{\mathrm{F}}$ in young calves, identifying the factors associated with AMU can help to reduce AMU in this age group. Besides management factors, it can be expected that mindset is also of importance in this context (Janz and Becker, 1984; Koelen and van den Ban, 2004). Both the farmers' mindset and calf management have proven to be essential factors in calf rearing and calf mortality (Santman-Berends et al., 2014), and are potentially associated with high AMU in young calves as well. The objective of our study was to evaluate the association between both young stock management and an indication of the farmers' related mindset and AMU in young calves on Dutch dairy farms with a high and with a low AMU in young calves.

\section{MATERIALS AND METHODS}

\section{Study Design and Study Population}

We applied a case-control design based on high or low AMU in young calves (0-56 d old). The study was restricted to conventional (nonorganic) farms, which included $98 \%$ of Dutch cattle farms in 2014 (CBS, 2016). The AMU registration in cattle in the Netherlands is mandatory and takes place in a national database called MediRund (ZuivelNL, The Hague, the Netherlands). We defined case farms as farms with a total DDDA $_{F}$ in young calves $>28$ in MediRund in both 2012 and 2013 (second quarter of 2012 until second quarter of 2014; high AMU). The total $\mathrm{DDDA}_{\mathrm{F}}$ in the MediRund database includes oral as well as parenteral AMU. Control farms were defined as farms with a total $\mathrm{DDDA}_{\mathrm{F}}$ in young calves $<0.5$ in both 2012 and 2013 (second quarter of 2012 until second quarter of 2014; low AMU). The cutoff for a high AMU was based on the 90th percentile of the AMU in young calves as re- ported by the SDa in 2012 (SDa, 2013a). The cutoff for a low AMU was based on the median use in 2012 and 2013 as reported by the SDa (SDa, 2013a, 2014), with the difference that a low use was allowed based on expert opinion. A sample size of 100 cases and 100 controls was considered sufficient to detect risk factors for a high AMU in young calves with an odds ratio of at least 2, with $95 \%$ confidence and $80 \%$ power, considering a risk factor prevalence of $50 \%$ in the control group. All conventional Dutch dairy farms that fulfilled the inclusion criteria of either the case or the control group were enrolled in the target population. Two separate Excel sheets (Microsoft Corp., Redmond, WA) for cases and controls were made and farmers were randomly approached by phone, using a random statement, until 100 participating cases and 100 participating controls were achieved.

\section{Data Collection}

A questionnaire was conducted by phone by 2 employees of GD Animal Health between July and October 2014. The cases and controls were randomly assigned to the interviewers, who were blind for the farm status (case or control). The questionnaire was developed by veterinarians with expertise in young stock rearing and was tested with the help of 1 dairy farmer and optimized afterward. The questionnaire included multiple- and single-choice questions about calving management and postnatal care (availability and surface of the maternity pen; hygiene; separation of calf and dam; administration of colostrum), calf housing (group housing versus individual housing; surface, location, age of the housing; climate issues; hygiene), and feeding management (provision of water; type of milk fed; feeding method of the milk; provision of other feed; amount of feed at weaning). In addition, questions were asked about the general animal health in the herd (e.g., bovine viral diarrhea herd status; Salmonella bulk milk status; health problems in young calves; vaccination of cows and young stock), breeds of the animals, knowledge of the farm AMU, and off-farm activities of the farmer. Farmers were asked about treatments and treatment durations in young calves (supportive measures versus antimicrobials; use of the herd treatment plan; reliance on the veterinarian). Their opinions concerning young stock, and concerning the treatment of animals and specifically young calves, were included in the questionnaire using statements for which farmers were requested to indicate whether they agreed or disagreed. These opinion statements were included as a proxy to explore the possible role of mindset relative to the role of technical factors. Examples of statements 
Table 1. Opinion statements in the questionnaire

\begin{tabular}{ll}
\hline Young stock & Use of antimicrobials \\
\hline $\begin{array}{l}\text { Young stock is the basis of my farm } \\
\begin{array}{l}\text { I spend more time taking care of my young stock than the } \\
\text { average farmer }\end{array}\end{array}$ & $\begin{array}{l}\text { Antimicrobials are necessary to keep problems in the herd under control } \\
\text { Antimicrobials are necessary to help sick animals }\end{array}$ \\
$\begin{array}{l}\text { With regard to young stock, I only do the work that is } \\
\text { most necessary }\end{array}$ & I use antimicrobials as little as possible due to the related costs \\
Young stock need specific management & $\begin{array}{l}\text { Antimicrobials should be used as little as possible because of public } \\
\text { health concerns }\end{array}$ \\
$\begin{array}{l}\text { As a result of the large amount of work on my dairy farm, } \\
\text { young stock has the lowest priority }\end{array}$ & \\
Young stock rearing is necessary, but not my thing & \\
\hline
\end{tabular}

included, "Young stock is the basis of my farm," "I only do what is necessary with regard to young stock," and "Young stock need specific management." Examples of statements with regard to the general opinion toward AMU included, "Antimicrobials are necessary on my farm to control problems," "Antimicrobials should be used as little as possible because of public health concerns," and "I only use antimicrobials if the veterinarian says it is necessary" (Table 1 ). The full questionnaire in Dutch is available on request.

In addition to the questionnaire, we used routinely collected herd data such as herd size, growth in herd size, replacement rate, purchase of cows, and mortality of cattle $<1$ yr old. These data were applicable to the period on which selection took place and were provided by the Dutch Enterprise Agency (RVO; the Hague, the Netherlands), Rendac (Son, the Netherlands), and GD Animal Health (Deventer, the Netherlands).

\section{Statistical Analysis}

In the analysis, all farms with a completed questionnaire were taken into account, with only a limited amount of information on variables missing for a few of the participating farms. Descriptive statistics, such as frequency distributions and summarizing statistics, were performed to describe the study population based on the questionnaire and the routinely collected data.

A logistic regression model in Stata 14.0 (StataCorp, 2015) was used for analysis, in which having a high (case) or low (control) $\mathrm{DDDA}_{\mathrm{F}}$ in young calves was included as the dependent variable. The information derived from the questionnaire, as well as routinely available data, were included as explanatory variables. First, the linearity of continuous variables was checked and nonlinear variables were categorized in quantiles (tertiles or quartiles). Variables with fewer than 5 observations in any category were exclusively analyzed univariably using a proportion test or chi-squared tests and described when significant. All other explanatory variables were prescreened in a univariable logistic regression model. Variables that were potentially associated with the AMU status $(P \leq 0.2)$ were subsequently considered in the multivariable logistic regression model. Collinearity between the variables was investigated by means of the bivariate correlation coefficients (Pearson and Spearman correlation coefficients). When a correlation of $\geq 0.5$ was observed, 1 of the 2 correlated variables (the least significant) was either removed or a new variable was created based on the combination of the correlated variables.

A manual forward model selection method was used to create the final multivariable model, in which only significantly associated variables $(P \leq 0.05)$ and confounding variables (i.e., that resulted in a substantial, $>25 \%$, change in coefficients of significantly associated variables) remained. In the final model, biologically relevant 2-way interaction terms were evaluated when possible and were included when significant. The explained variability of the model was presented using the McFadden pseudo coefficient of determination.

\section{RESULTS}

In total, 311 dairy farmers were contacted by telephone, of which 200 (64\%) were willing to participate. Reasons for nonparticipation included not being interested in the questionnaire, not having enough time, planning to stop farming, and being concerned about privacy. The results of 1 farm were excluded from the analysis because that farm outsourced young stock raising. The results of 4 farms were excluded because the farmers did not provide the written consent allowing us to use the data collected. In total, results from 195 farms (97 high-AMU farms and 98 low-AMU farms) remained for analysis.

High-AMU farms had a median herd size of 103 cows ( $>2$ yr old; mean of 133). Low-AMU farms had a median herd size of 74 cows ( $>2$ yr old; mean of 85 ). The median percentage of growth in herd size during the 
Table 2. Results of the final multivariable logistic regression model for high antimicrobial usage (AMU; case) versus low AMU (control) in young calves in Dutch dairy herds in the Netherlands in 2012 and $2013(\mathrm{n}=183: 87 \text { cases and } 96 \text { controls })^{1}$

\begin{tabular}{|c|c|c|c|c|c|}
\hline Variable & Category & $\mathrm{N}$ & $\begin{array}{l}\text { Odds } \\
\text { ratio }\end{array}$ & $\begin{array}{c}95 \% \\
\mathrm{CI}\end{array}$ & $P$-value \\
\hline $\begin{array}{l}\text { Usually start treatment of a sick young calf with } \\
\text { supportive measures (electrolytes, preparations } \\
\text { without antimicrobials, anti-inflammatories) }\end{array}$ & Yes & 127 & & Referent & \\
\hline \multirow[t]{2}{*}{ Type of housing (group housing of calves $0-56 \mathrm{~d}$ old) } & Non-slatted floor with bedding & 116 & & Referent & \\
\hline & $\begin{array}{l}\text { Partially slatted floor with } \\
\text { bedding }\end{array}$ & 48 & 4.6 & $1.5-13.4$ & $<0.01$ \\
\hline $\begin{array}{l}\text { "Young stock need specific management" } \\
\text { (agree with the statement) }\end{array}$ & No & 42 & 4.1 & $1.4-12.1$ & 0.01 \\
\hline \multirow{3}{*}{$\begin{array}{l}\text { Percentage of young calves in the herd with respiratory } \\
\text { problems }\end{array}$} & $0 \%$ & 118 & & Referent & \\
\hline & $0-10 \%$ & 33 & 0.3 & $0.1-1.2$ & 0.08 \\
\hline & $>10 \%$ & 32 & 2.3 & $0.6-8.5$ & 0.21 \\
\hline \multirow{3}{*}{$\begin{array}{l}\text { Unfavorable Salmonella bulk milk results from the last } \\
5 \text { tests? } \\
\text { Do you know the overall animal daily-defined dose of } \\
\text { your farm in } 2013 \text { ? }\end{array}$} & No & 145 & & Referent & \\
\hline & Yes, at least 1 unfavorable result & 38 & 3.3 & $1.1-10.2$ & 0.04 \\
\hline & No & 81 & & Referent & \\
\hline
\end{tabular}

${ }^{1}$ Confounders: average number of calves (0-1 year old) present on the farm during the study period and the use of group treatment in calves.

${ }^{2}$ Different $=$ slatted floor with cubicles $(\mathrm{n}=12)$, fully slatted floor $(\mathrm{n}=4)$, sand and straw $(\mathrm{n}=2)$, or rubber with sawdust $(\mathrm{n}=1)$.

analyzed period in high- and low-AMU farms was 3.5 $($ mean $=4.2 \%)$ and $3.3 \%($ mean $=17.5 \%)$, respectively. The median replacement rate was $24.5 \%$ (mean $25.0 \%$ ) in high-AMU farms and $23.7 \%$ (mean 24.0\%) in lowAMU farms. The median mortality rate in calves was $3.0 \%$ in high-AMU farms and $2.3 \%$ in low-AMU farms (mean of 3.9 and $2.9 \%$, respectively).

In total, 44 variables (out of 166 variables that were evaluated) were potentially associated with the AMU status in the univariable analysis $(P \leq 0.2)$. These variables are described in Supplemental Table S1 (https:// doi.org/10.3168/jds.2018-14252). Variables with sufficient observations in all categories that were not univariably associated with the AMU status $(P>0.2)$ are presented in Supplemental Table S2 (https://doi.org/ 10.3168/jds.2017-14252). After combining certain variables due to high correlations and the removal of 1 of the highly correlated variables (retaining the variable that was considered to contain the most relevant information), 32 variables were evaluated in the multivariable model. The final multivariable model contained 6 variables and 2 confounders (Table 2).

Herds of farmers who indicated that they usually did not start treatment with supportive products had 11.4 times higher odds of belonging to the high-AMU group than herds with farmers who indicated that they usually started the treatment with supportive products, such as electrolytes, preparations without antimicrobials, and anti-inflammatories. Farms in which young calves $(0-56$ d old) were housed on partially slatted floors instead of nonslatted floors (complete straw or sawdust bedding) had a 4.6 times higher odds of being classified as a
high-AMU farm. Farmers who disagreed with the statement "young stock need specific management" belonged to the high-AMU group more often than farmers who agreed with this statement (odds ratio $=4.1$ ). In addition, farmers who indicated that $>10 \%$ of their young calves had respiratory problems more often belonged to the high-AMU group than farmers who indicated that 0 to $10 \%$ of their young calves had respiratory problems (odds ratio $=8.1,95 \% \mathrm{CI}=1.5-43.2, P=0.02$ ).

Finally, farmers with an indication of a Salmonella infection based on positive bulk milk testing or farmers who knew their overall $\mathrm{DDDA}_{\mathrm{F}}$ of the previous year also had higher odds of being classified as a high-AMU farm than other farms. The pseudo-coefficient of determination of the final model was $45.9 \%$. In total, $82.5 \%$ of the farms were correctly predicted to be either a low- or high-AMU farm (sensitivity $=80.5 \%$, specificity $=84.4 \%$ ).

In total, 16 variables that could not be taken into account in the multivariable analyses due to a lack of sufficient observations in 1 of the categories were significantly associated with the farm AMU status $(P$ value proportion test $\leq 0.05$ or $P$-value chi-squared test $\leq 0.05)$. These variables are presented in Supplemental Table S3 (https://doi.org/10.3168/jds.2017-14252).

\section{DISCUSSION}

Several management-related factors were identified as important with regard to a high or low AMU in young calves. Farms that were classified as high AMU housed calves more frequently on partially slatted 
floors. This is consistent with the findings of Gulliksen et al. (2009), who indicated that slatted floors in group housing are a risk factor for the development of diarrhea in calves. In addition, farmers of high-AMU herds more often indicated that their herd tested positive for Salmonella based on bulk milk testing. Salmonella is known to be associated with calf diarrhea (Reynolds et al., 1986) and may lead to antimicrobial treatments (Constable, 2004) and, thus, contribute to a high AMU. Both, digestive disorders or diarrhea and respiratory problems are known to be important indications for AMU in calves (González et al., 2010; Pardon et al., 2012). In our study, farmers who indicated that $>10 \%$ of their calves had respiratory problems more often belonged to the high-AMU group than farmers who indicated that 0 to $10 \%$ of their calves had respiratory problems. Remarkably, the odds of being a high-AMU farm were lower for farms with respiratory problems in $>0$ to $10 \%$ of the calves than for farms with $0 \%$ respiratory problems. We have no explanation for this result, except that $0 \%$ respiratory problems is somewhat unrealistic and thus possibly represents a group of farms that was underreporting disease due to poor disease awareness. It is not likely that farms with a low AMU are underreporting their AMU, because the registration of AMU is obligatory in the Netherlands. Although illegal purchase of antimicrobials cannot be fully excluded, we know of no reason for such practices with respect to treating young calves.

We took all qualified variables into account when selecting the multivariable model. It is possible that disease estimates, such as the presence of respiratory problems, took away variation that might be explained by other variables that did not end up in the final model. Therefore, we performed another model selection without including the variables representing disease estimates. The resulting final model, however, was similar to the original model, except that 2 additional variables were significant: the number of cattle $<1 \mathrm{yr}$ old in the herd and the statement "I use antimicrobials as little as possible due to the related costs."

Farms with a higher number of cattle $<1$ yr old more often belonged to the high-AMU group. Svensson and Liberg (2006) investigated the effect of group size in Swedish dairy calves housed in pens with automatic milk feeders and found that calves housed in pens with 12 to 18 calves had a higher incidence of respiratory illness than calves housed in pens with 6 to 9 calves. Comparable results were found in veal calves by Abdelfattah et al. (2013). The maximum number of calves housed in 1 group was not associated with the AMU in our study. The exact rationale behind this result therefore remains unclear. It is very likely that the as- sociation between the number of calves and the AMU status is due to co-occurring factors.

Farmers belonging to the high-AMU group less often agreed with the statement "I use antimicrobials as little as possible due to the related costs" than farmers in the low-AMU group did. This can be associated with the disease status. Farms with a high AMU had a higher disease incidence, and therefore might be more aware of its detrimental effect on health and welfare, which is likely to be a more important motivator when considering treatment than the costs.

In both final models, a strong association was found between the statement "I usually start the treatment of a sick young calf with supportive products" and having a low AMU in young calves. The decision not to always start a treatment with antimicrobials was found to be related to lower AMU. However, it is unknown whether or not these farms applied these supportive measures when they should have started treatment with antimicrobials. Withholding the correct treatment might have an adverse effect on animal health and welfare. The decision to start supportive or antimicrobial treatment might be determined by the farmers' mindset, and specifically by the perceived threat (Jansen et al., 2016) of not treating calves directly with antimicrobials. In our study, high-AMU farmers seemed to be aware of their high use based on the fact that they knew their own DDDA $A_{F}$ more often than farmers with a low AMU; however, the high-AMU farmers did agree less often with the statement "Young stock need specific management." The importance of specific management for young stock should be emphasized to high-AMU farmers using tailored communication, for example.

During the study, we encountered some challenges in the selection of appropriate case and control farms, issues related to socially desirable answers, the timelag between selection and interviews, and the use of opinion statements. First, in our study, AMU used for selecting high- and low-AMU farms comprised the total use in young calves (both oral and parenteral use). The cutoffs for defining the high and low use groups were based on reports on the AMU in young calves (0-56 d old) by the SDa (SDa, 2013a, 2014). These reports only include oral AMU in young calves, which might have resulted in a lower threshold to assign farms to the high-AMU group. Nevertheless, a total AMU above $28 \mathrm{DDDA}_{\mathrm{F}}$ is a relatively high AMU and is very different from the threshold for a low AMU, 0.5 DDDAF. This is supported by the results of the Dutch Cattle Health Monitoring System (Santman-Berends et al., 2016), in which a large majority of dairy farms had a total $\mathrm{DDDA}_{\mathrm{F}}<28$ in calves 0 to $56 \mathrm{~d}$ old. Second, the fact that AMU is an important topic in the Nether- 
lands may have resulted in socially desirable answers, which can lead to an underestimation of true effects. To prevent this type of bias as much as possible, clear questions were asked, farmers were not informed about their AMU status, and farmers were told that their answers would be processed anonymously. Third, the time lag between the period during which the farm status was determined and the interviews might have influenced the results. Farms were selected as high- or low-AMU farms based on their AMU in young calves in 2012 and 2013, whereas the interview was conducted in 2014; this may have led to recall bias. Control group farmers likely recalled less disease events and related possible risk factors than case group farmers. Although AMU and management may have changed during the time lag, the $\mathrm{DDDA}_{\mathrm{F}}$ was still high in the majority of high-AMU farms in 2014 (results not presented); thus, the case-control classification seems robust. Finally, we used an agree or disagree answer possibility with regard to the opinion statements instead of a of Likert scale. This allows for a quicker detection of significant differences but does not allow for scaling of the degree of agreement, which could have resulted in a more nuanced answer by the farmer.

Our study provided insight into factors that may increase a more prudent AMU in young calves on dairy farms with a high $\mathrm{DDDA}_{\mathrm{F}}$ in that specific age group. However, it must be noted that our study focused on differences between high- and low-AMU farms, thus the results cannot be generalized to all dairy farms. The associated factors were related to disease estimates, to young stock management and to the farmers' opinion on young stock management. When defining strategies to decrease the AMU in young calves on high-AMU farms, the influence of the farmers' opinions, indicative for mindset, should be considered in addition to discussing technical issues. We recommend future research focus both on the role of technical aspects as well as on the role of mindset, which will allow farmers to be stratified into high-risk profiles, enabling targeting in a tailored way. Although the rationale behind AMU in young calves warrants more research, we concluded that both management and mindset are likely to be associated with the farm AMU in young dairy calves.

\section{ACKNOWLEDGMENTS}

This study was financed by ZuivelNL (The Hague, the Netherlands) and took place in collaboration with the Institute for Risk Assessment Sciences (IRAS, Utrecht, the Netherlands). We thank the farmers for their participation in this study. In addition, we thank the reviewers whose suggestions helped to improve and clarify this manuscript.

\section{REFERENCES}

Abdelfattah, E. M., M. M. Schutz, D. C. Lay Jr., J. N. MarchantForde, and S. D. Eicher. 2013. Effect of group size on behavior, health, production and welfare of veal calves. J. Anim. Sci. 91:5455-5465. https://doi.org/10.2527/jas.2013-6308.

CBS. 2016. Landbouw; biologisch en/of omschakeling, dieren (Agriculture, biological and/or switch-overs, animals). Accessed Dec. 21, 2016. http://statline.cbs.nl/Statweb/publication/?DM=SLNL\& $\mathrm{PA}=81558 \mathrm{ned} \& \mathrm{D} 1=\mathrm{a} \& \mathrm{D} 2=\mathrm{a} \& \mathrm{D} 3=0,13,17,28 \& \mathrm{D} 4=\mathrm{l} \& \mathrm{HDR}=\mathrm{G} 2$ , G1,G3\&STB $=\mathrm{T} \& \mathrm{VW}=\mathrm{T}$.

Chirila, F., A. Tabaran, N. Fit, G. Nadas, M. Mihaiu, F. Tabaran, C. Catoi, O. L. Reget, and S. D. Dan. 2017. Concerning increase in antimicrobial resistance in Shiga Toxin-producing Escherichia coli isolated from young animals during 1980-2006. Microbes Environ. 32:252-259. https://doi.org/10.1264/jsme2.ME17023.

Constable, P. D. 2004. Antimicrobial use in the treatment of calf diarrhea. J. Vet. Intern. Med. 18:8-17.

González, S. M., A. Steiner, B. Gassner, and G. Regula. 2010. Antimicrobial use in Swiss dairy farms: Quantification and evaluation of data quality. Prev. Vet. Med. 95:50-63. https://doi.org/10.1016/j .prevetmed.2010.03.004.

Gulliksen, S. M., E. Jor, K. L. Lie, I. S. Hamnes, T. Løken, J. Akerstedt, and O. Osterås. 2009. Enteropathogens and risk factors for diarrhea in Norwegian diary calves. J. Dairy Sci. 92:5057-5066. https://doi.org/10.3168/jds.2009-2080.

Hinton, M., A. H. Linton, and A. J. Hedges. 1985. The ecology of Escherichia coli in calves reared as dairy-cow replacements. J. Appl. Bacteriol. 58:131-138.

Hinton, M., P. D. Rixson, V. Allen, and A. H. Linton. 1984. The persistence of drug resistant Escherichia coli strains in the majority faecal flora of calves. J. Hyg. (Lond.) 93:547-557.

Jansen, J., R. J. Wessels, and T. J. G. M. Lam. 2016. Understanding the mastitis mindset: Applying social psychology in practice. Pages 5-15 in Proc. National Mastitis Council 55th Annual Meeting, Glendale, AZ.

Janz, N. K., and M. H. Becker. 1984. The health belief model: A decade later. Health Educ. Q. 11:1-7.

Koelen, M. A., and A. W. van den Ban. 2004. Health Education and Health Promotion. Wageningen Academic Publishers. Wageningen, the Netherlands.

Pardon, B., B. Catry, J. Dewulf, D. Persoons, M. Hostens, K. De Bleecker, and P. Deprez. 2012. Prospective study on quantitative and qualitative antimicrobial and anti-inflammatory drug use in white veal calves. J. Antimicrob. Chemother. 67:1027-1038. https://doi.org/10.1093/jac/dkr570.

Reynolds, D. J., J. H. Morgan, N. Chanter, P. W. Jones, J. C. Bridger, T. G. Debney, and K. J. Bunch. 1986. Microbiology of calf diarrhea in southern Britain. Vet. Rec. 119:34-39.

Santman-Berends, I. M. G. A., H. Brouwer-Middelesch, L. van Wuijckhuise, A. J. G. de Bont-Smolenaars, and G. van Schaik. 2016. Surveillance of cattle health in the Netherlands: Monitoring trends and developments using routinely collected bovine census data. Prev. Vet. Med. 134:103-112. https://doi.org/10.1016/j.prevetmed .2016.10.002.

Santman-Berends, I. M. G. A., M. Buddiger, A. J. Smolenaars, C. D. Steuten, C. A. Roos, A. J. van Erp, and G. van Schaik. 2014. A multidisciplinary approach to determine factors associated with calf rearing practices and calf mortality in dairy herds. Prev. Vet. Med. 117:375-387. https://doi.org/10.1016/j.prevetmed.2014.07 .011 .

SDa. 2013a. Usage of Antibiotics in Agricultural Livestock in the Netherlands in 2012. Accessed Oct. 31, 2017. http://www .autoriteitdiergeneesmiddelen.nl/Userfiles/pdf/sda-report-usage-of -antibiotics-in-livestock-in-the-netherlands-in-2012-july-2013.pdf. 
SDa. 2013b. Standard Operating Procedure (SOP) Calculation of the $\mathrm{DDD} / \mathrm{J}$ for antimicrobials by the SDa for the cattle-, veal, pig- and poultrysector. Accessed Oct. 31, 2017. http://www .autoriteitdiergeneesmiddelen.nl/Userfiles/pdf/sda-standard -operating-procedure-(sop)-juni-2013-def.pdf.

SDa. 2014. Usage of Antibiotics in Agricultural Livestock in the Netherlands in 2013. Accessed Oct. 31, 2017. http://www .autoriteitdiergeneesmiddelen.nl/Userfiles/AB\%20gebruik\%20 2013/sda-report-usage-of-antibiotics-2013-september-2014.pdf.

SDa. 2015. Usage of Antibiotics in Agricultural Livestock in the Netherlands in 2014; Trends and benchmarking of livestock farms and veterinarians. Accessed Oct. 31, 2017. http://www .autoriteitdiergeneesmiddelen.nl/Userfiles/pdf/SDa-rapporten/ def-sda-rapport-ab-2014-engels-v2-aangepast-102015-incl-erratum .pdf.

StataCorp. 2015. Stata Statistical Software: Release 14. StataCorp LP, College Station, TX.

Svensson, C., and P. Liberg. 2006. The effect of group size on health and growth rate of Swedish dairy calves housed in pens with automatic milk-feeders. Prev. Vet. Med. 73:43-53. https://doi.org/10 .1016/j.prevetmed.2005.08.021.

Zhang, X. L., F. Wang, D. M. Zhu, S. Wu, P. C. Wu, Y. D. Chen, Y. Q. Wang, and L. Zhou. 1998. The carriage of Escherichia coli resistant to antibiotics in healthy populations in Shanghai. Biomed. Environ. Sci. 11:314-320. 